\title{
SCIENTIFIC REPORTS

\section{OPEN Botryane terpenoids produced by Nemania bipapillata, an endophytic fungus isolated from \\ red alga Asparagopsis taxiformis - Falkenbergia stage}

Received: 26 September 2018

Accepted: 8 August 2019

Published online: 23 August 2019
Rebeca P. Medina ${ }^{1}$, Angela R. Araujo ${ }^{1}$, João M. Batista Jri( ${ }^{2,3}$, Carmen L. Cardoso ${ }^{4}$, Cláudia Seidl $\mathbb{1}^{4}$, Adriana F. L. Vilela ${ }^{4}$, Helori V. Domingos ${ }^{5}$, Leticia V. Costa-Lotufo ${ }^{5}$, Raymond J. Andersen ${ }^{6}$ \& Dulce H. S. Silva $\mathbb{1}^{1}$

A chemical study of the EtOAc extract of Nemania bipapillata (AT-05), an endophytic fungus isolated from the marine red alga Asparagopsis taxiformis - Falkenbergia stage, led to the isolation of five new botryane sesquiterpenes, including the diastereomeric pair $(+)-(2 R, 4 S, 5 R, 8 S)-(1)$ and (+)-(2R,4R,5R,8S)-4-deacetyl-5-hydroxy-botryenalol (2), (+)-(2R,4S,5R,8R)-4-deacetyl-botryenalol (3), one pair of diastereomeric botryane norsesquiterpenes bearing an unprecedented degraded carbon skeleton, $(+)-(2 R, 4 R, 8 R)-(4)$ and $(+)-(2 R, 4 S, 8 S)-(5)$, which were named nemenonediol $A$ and nemenonediol $B$, respectively, in addition to the known $4 \beta$-acetoxy-9 $3,10 \beta, 15 \alpha-$ trihydroxyprobotrydial (6). Their structures were elucidated using 1D and 2D NMR, HRESIMS and comparison with literature data of similar known compounds. The absolute configurations of 2, 3 and 4 were deduced by comparison of experimental and calculated electronic circular dichroism (ECD) spectra, while those of 1 and 5 were assigned from vibrational circular dichroism (VCD) data. Compound 4 weakly inhibited acetylcholinesterase, whereas compound 1 inhibited both acetylcholinesterase and butyrylcholinesterase. Compounds 1, 3, 5 and 6 were tested against two carcinoma cell lines (MCF-7 and HCT-116), but showed no significant citotoxicity at tested concentrations $\left(\mathrm{IC}_{50}>50 \mu \mathrm{M}\right)$.

Recent studies on marine-derived endophytic microorganisms have shown their potential as a source of new bioactive natural products ${ }^{1}$. As part of our ongoing efforts to identify new secondary metabolites produced by endophytic fungi isolated from the red alga Asparagopsis taxiformis (Falkenbergia stage) ${ }^{2}$, we have investigated extracts of laboratory cultures of the fungus Nemania bipapillata. This chemical study led to the isolation of one known and five new botryane terpenoids, including two pairs of diastereomeric compounds.

The genus Nemania belongs to the family Xylariaceae, one of the largest of Ascomycota phylum ${ }^{3}$, and has shown interesting applications associated with its bioactive small molecules as well as in biocatalysis. Nemania serpens was isolated as a fungal endophyte from Anemopsis californica, a plant used as a traditional medicine to treat infections due to its antibacterial activity against Staphylococcus aureus and Pseudomonas aeruginosa $a^{4}$. Nemania aenea SF10099-1, isolated from a forest soil sample was used as a bioacatalyst in the regio- and

\footnotetext{
${ }^{1}$ Núcleo de Bioensaios, Biossíntese e Ecofisiologia de Produtos Naturais (NuBBE), Departamento de Química Orgânica, Instituto de Química, UNESP - Universidade Estadual Paulista, 14801-970, Araraquara-SP, Brazil. 2Departamento de Química, Centro de Ciências Exatas e de Tecnologia, Universidade Federal de São Carlos UFSCar, 13565-905, São Carlos-SP, Brazil. ${ }^{3}$ Departamento de Ciência e Tecnologia, Universidade Federal de São Paulo-UNIFESP, 12231-280, São José dos Campos-SP, Brazil. ${ }^{4}$ Grupo de Cromatografia de Bioafinidade e Produtos Naturais, Departamento de Química, Faculdade de Filosofia, Ciências e Letras de Ribeirão Preto, Universidade de São Paulo, 14040-901, Ribeirão Preto-SP, Brazil. Instituto de Ciências Biomédicas, Universidade de São Paulo, 05508-900, São Paulo-SP, Brazil. ${ }^{6}$ Departments of Chemistry and Earth, Ocean \& Atmospheric Sciences, University of British Columbia, V6T 1Z1, Vancouver, BC, Canada. Correspondence and requests for materials should be addressed to D.H.S.S. (email: dulce.silva@unesp.br)
} 


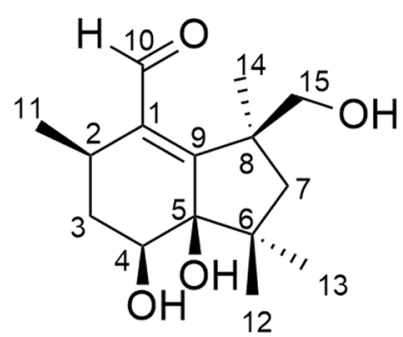

1

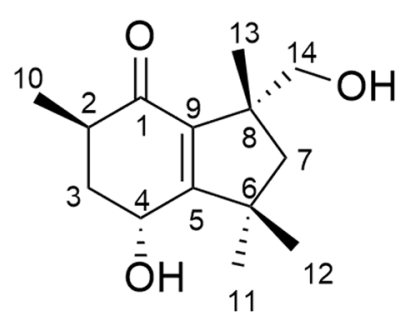

4

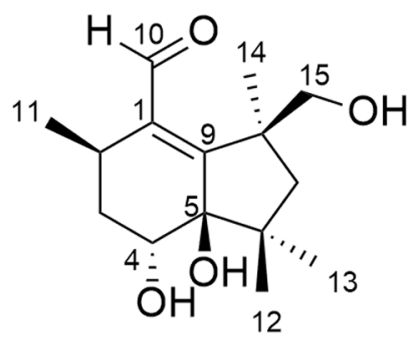

2

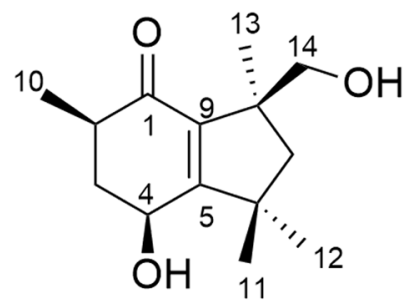

5

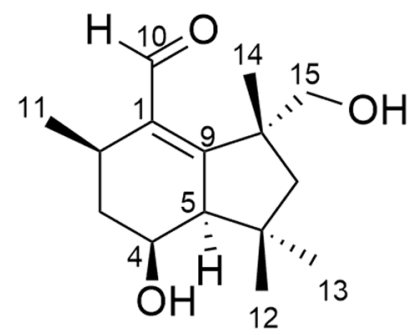

3

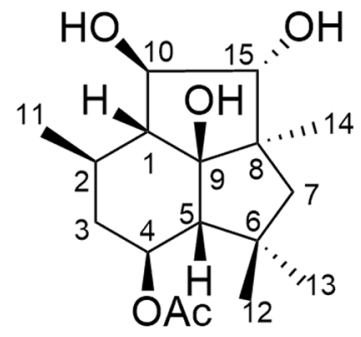

6

Figure 1. Botryane terpenoids isolated from EtOAc extract of Nemania bipapillata cultures.

stereoselective synthesis of (-)- $\beta$-caryophyllene oxide using $\beta$-caryophyllene as substrate in a liquid-liquid interface bioreactor ${ }^{5}$.

Acetylcholinesterase (EC 3.1.1.7) (AChE) and butyrylcholinesterase (EC 3.1.1.8) (BChE) have gained attention due to their roles in Alzheimer disease (AD) and other Central Nervous System (CNS) conditions, such as delirium and traumatic brain injuries, associated with deficient levels of acetylcholine (ACh) ${ }^{6}$. Galanthamine, a natural alkaloid first isolated from the plant Galanthus spp. (Amaryllidaceae), is one of the few drugs currently available for the treatment of $\mathrm{AD}$, which inhibits the AChE activity, increasing the levels of ACh in the brain and prolonging cholinergic functions ${ }^{7}$. Diterpenoids have been shown to be cholinesterase inhibitors ${ }^{8-11}$, which stimulated our interest in investigating the potential anticholinesterase activity of the new terpenoids isolated from Nemania bipapillata.

The search for new cancer chemotherapeutic agents has increased in the last years due to the drug resistance in cancer treatment. Natural sesquiterpenes have demonstrated cytotoxic activity ${ }^{12}$, including botrydial, a botryane sesquiterpene, and its derivatives ${ }^{13}$. In this paper, we describe the isolation and structure elucidation of three new botryane sesquiterpenes (1-3) and two norsesquiterpenes with a new degraded carbon skeleton (4 and 5) (Fig. 1), the determination of their absolute configurations, and their activities as cholinesterase inhibitors and cytotoxic agents.

For the determination of the absolute configuration of compounds 1-5, electronic and vibrational circular dichroism spectroscopies (ECD and VCD, respectively) were used with the aid of quantum chemical calculations. ECD and VCD methods are based on the differential absorption of left- and right-circularly polarized UV or IR radiation, respectively, by a chiral molecule during electronic or vibrational transitions. Both chiroptical methods have been successfully used over the years for absolute configuration assignments of a large array of chiral molecules including natural products ${ }^{14,15}$.

\section{Results and Discussion}

The EtOAc extract of Nemania bipapillata (AT-05) cultures was fractionated using a reversed-phase flash chromatography column to give 4 fractions (AT-05-F1 - AT-05-F4). Further purification of fraction AT-05-F2 using reversed-phase HPLC yielded five new compounds 1-5, in addition to the known compound 6 (Fig. 1). Their structures were elucidated via detailed analysis of NMR and mass spectrometry data, in addition to ECD and VCD analyses to determine their absolute configurations.

Compound 1 gave a $[\mathrm{M}+\mathrm{Na}]^{+}$ion at $m / z 291.1576$ in the ESITOFHRMS appropriate for a molecular formula of $\mathrm{C}_{15} \mathrm{H}_{24} \mathrm{O}_{4}$ (calcd for $\mathrm{C}_{15} \mathrm{H}_{24} \mathrm{O}_{4} \mathrm{Na} 291.1572$ ) requiring 4 sites of unsaturation. The ${ }^{1} \mathrm{H}$ NMR (Table 1 ) and HSQC spectra revealed the presence of four methyl groups, associated with three singlets $\left(\delta 1.20 / \mathrm{H}_{3}-12,1.00 /\right.$ $\mathrm{H}_{3}-13$ and $\left.1.40 / \mathrm{H}_{3}-14\right)$ and one doublet $\left(\delta 1.03, J_{11-2} 6.6 \mathrm{~Hz}, \mathrm{H}_{3}-11\right)$, one hydroxymethine proton at $\delta 3.73\left(\mathrm{dd}, J_{4-3 \mathrm{a}}\right.$ $\left.4.2, J_{4-3 \mathrm{~b}} 12.0 \mathrm{~Hz}, \mathrm{H}-4\right)$ and a set of nonequivalent oxymethylene protons at $\delta 3.71\left(\mathrm{~d}, J_{15 \mathrm{a}-15 \mathrm{~b}} 10.2 \mathrm{~Hz}, \mathrm{H}_{\mathrm{a}}-15\right) / 3.57$ $\left(\mathrm{d}, J_{15 \mathrm{~b}-15 \mathrm{a}} 10.2 \mathrm{~Hz}, \mathrm{H}_{\mathrm{b}}-15\right)$, in addition to one aldehyde proton $(\delta 10.28, \mathrm{~s}, \mathrm{H}-10)$. The ${ }^{1} \mathrm{H}-{ }^{1} \mathrm{H}$ COSY spectrum (Supplementary Fig. S4) showed correlations of a methine proton at $\delta 2.73(\mathrm{~m}, \mathrm{H}-2)$ to methylene hydrogens at $\delta 1.81\left(\mathrm{~m}, \mathrm{H}_{\mathrm{a}}-3,1 \mathrm{H}\right)$ and $\delta 1.67\left(\mathrm{~m}, \mathrm{H}_{\mathrm{b}}-3,1 \mathrm{H}\right)$ and to $\mathrm{H}_{3}-11$ (Fig. 2). The ${ }^{13} \mathrm{C}$ NMR data (Table 2) exhibited one carbonyl carbon at $\delta 197.1(\mathrm{C}-10)$, which correlated with the proton at $\delta 10.28$, as shown in the HSQC spectrum (Supplementary Fig. S5), and two quaternary sp ${ }^{2}$ carbons ( $\left.\delta 141.8 / \mathrm{C}-1,164.7 / \mathrm{C}-9\right)$, suggesting the presence of an 


\begin{tabular}{|l|l|l|l|l|l|}
\hline Position & $\mathbf{1}$ & $\mathbf{2}$ & $\mathbf{3}$ & $\mathbf{4}$ & $\mathbf{5}$ \\
\hline 2 & $2.73(\mathrm{~m})$ & $2.91(\mathrm{~m})$ & $2.79(\mathrm{~m})$ & $2.78(\mathrm{~m})$ & $2.43(\mathrm{~m})$ \\
\hline \multirow{2}{*}{3} & $1.81(\mathrm{~m})$ & $1.80(\mathrm{~m})$ & $2.02(\mathrm{ddd}, 3.9,6.5,12.8)$ & $2.09(\mathrm{~m})$ & $2.27(\mathrm{~m})$ \\
\cline { 2 - 6 } & $1.67(\mathrm{~m})$ & & $1.29(\mathrm{~m})$ & $1.95(\mathrm{~m})$ & $1.75(\mathrm{~m})$ \\
\hline 4 & $3.73(\mathrm{dd}, 4.2,12.0)$ & $4.10(\mathrm{dd}, 3.6,6.9)$ & $3.62(\mathrm{ddd}, 3.9,8.7,11.1)$ & $4.43(\mathrm{t}, 3.0)$ & $4.69(\mathrm{dd}, 4.8,10.2)$ \\
\hline 5 & & & $2.33(\mathrm{dd}, 3.3,8.7)$ & & \\
\hline \multirow{2}{*}{7} & $2.23(\mathrm{~d}, 13.0)$ & $2.26(\mathrm{~d}, 12.6)$ & $1.88(\mathrm{~d}, 13.2)$ & $1.96(\mathrm{~d}, 13.2)$ & $1.93(\mathrm{~d}, 13.8)$ \\
\cline { 2 - 7 } & $1.24(\mathrm{~d}, 13.0)$ & $1.19(\mathrm{~d}, 12.6)$ & $1.40(\mathrm{~d}, 13.2)$ & $1.53(\mathrm{~d}, 13.2)$ & $1.53(\mathrm{~d}, 13.8)$ \\
\hline 10 & $10.28(\mathrm{~s})$ & $10.26(\mathrm{~s})$ & $10.21(\mathrm{~s})$ & $1.10(\mathrm{~d}, 7,2)$ & $1.10(\mathrm{~d}, 6.6)$ \\
\hline 11 & $1.03(\mathrm{~d}, 6.6)$ & $1.05(\mathrm{~d}, 7.2)$ & $1.06(\mathrm{~d}, 7.2)$ & $1.32(\mathrm{~s})$ & $1.38(\mathrm{~s})$ \\
\hline 12 & $1.20(\mathrm{~s})$ & $1.15(\mathrm{~s})$ & $0.98(\mathrm{~s})$ & $1.20(\mathrm{~s})$ & $1.31(\mathrm{~s})$ \\
\hline 13 & $1.00(\mathrm{~s})$ & $1.16(\mathrm{~s})$ & $1.25(\mathrm{~s})$ & $1.19(\mathrm{~s})$ & $1.13(\mathrm{~s})$ \\
\hline \multirow{2}{*}{14} & $1.40(\mathrm{~s})$ & $1.48(\mathrm{~s})$ & $1.44(\mathrm{~s})$ & $3.63(\mathrm{~d}, 10.8)$ & $3.57(\mathrm{~d}, 10.8)$ \\
\cline { 2 - 7 } & & & & $3.42(\mathrm{~d}, 10.8)$ & $3.54(\mathrm{~d}, 10.8)$ \\
\hline \multirow{2}{*}{15} & $3.71(\mathrm{~d}, 10.2)$ & $3.71(\mathrm{~d}, 10.2)$ & $3.52(\mathrm{~d}, 10.8)$ & & \\
\cline { 2 - 7 } & $3.57(\mathrm{~d}, 10.2)$ & $3.57(\mathrm{~d}, 10.2)$ & $3.58(\mathrm{~d}, 10.8)$ & & \\
\hline
\end{tabular}

Table 1. ${ }^{1} \mathrm{H}$ NMR data ( $\delta$ in ppm, mult., $J$ in $\left.\mathrm{Hz}\right)$ of $\mathbf{1 - 5}\left(600 \mathrm{MHz} ; \mathrm{CD}_{3} \mathrm{OD}\right)$.

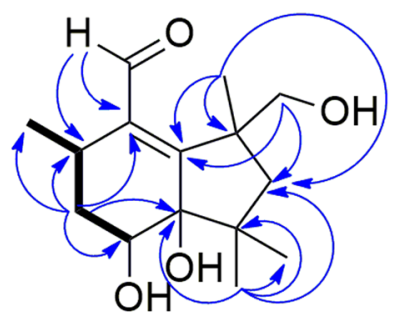

1

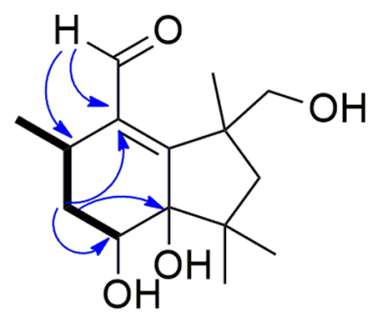

2

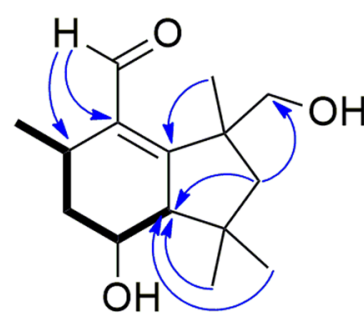

3

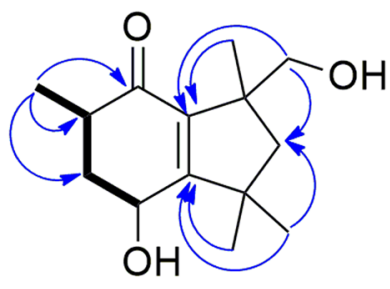

4

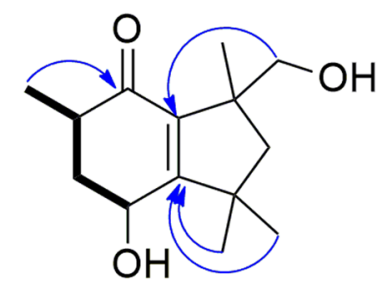

5

Figure 2. COSY (bold bonds) and key HMBC (blue arrows) correlations of compounds 1-5.

$\alpha, \beta$-unsaturated carbonyl group, in addition to three quaternary $\mathrm{sp}^{3}(\delta 44.6 / \mathrm{C}-6,47.9 / \mathrm{C}-8,83.1 / \mathrm{C}-5)$ hybridized carbons. The HMBC spectrum (Supplementary Fig. S6) evidenced correlations of H-10 to C-1 and C-2 ( $\delta 31.5)$, of $\mathrm{H}_{\mathrm{a}}-3$ to C-1, C-4 ( $\left.\delta 69.9\right)$ and C-5, of $\mathrm{H}_{\mathrm{b}}-3$ to C-2, C-4 ( $\left.\delta 69.9\right)$ and C-11 ( $\left.\delta 20.9\right)$, of $\mathrm{H}_{3}-12$ to C-5, C-6, C-7 ( $\delta 53.4)$ and $\mathrm{C}-13$ ( $\delta 26.6$ ), of $\mathrm{H}_{3}-14$ to $\mathrm{C}-7, \mathrm{C}-8$ and $\mathrm{C}-9$, as well as correlations of $\mathrm{H}_{\mathrm{a}}-15$ and $\mathrm{H}_{\mathrm{b}}-15$ to $\mathrm{C}-7$ and C-9, respectively (Fig. 2). The ${ }^{1} \mathrm{H}$ NMR spectrum of compound 1 obtained in DMSO- $d_{6}$ displayed signals for the hydroxyl protons at $\delta 5.40\left(\mathrm{t}, J_{15-0 \mathrm{H}-15} 4.8 \mathrm{~Hz}, 15-\mathrm{OH}, 1 \mathrm{H}\right), 4.33(\mathrm{~s}, 5-\mathrm{OH}, 1 \mathrm{H})$, and $4.23\left(\mathrm{~d}, J_{4-\mathrm{OH}-4} 7.2 \mathrm{~Hz}, 4-\mathrm{OH}\right.$, $1 \mathrm{H})$ (Supplementary Table S1 and Fig. S7). ROESY (DMSO- $d_{6}$ ) correlations revealed the relative configuration of 1 (Supplementary Fig. S9). The 4-OH and 5-OH signals showed ROESY correlations to $\mathrm{H}_{3}-12(\delta 1.09 \mathrm{~s}, 3 \mathrm{H})$, whereas the H-4 signal $\left(\delta 3.53\right.$, ddd, $\left.J_{4-3 \mathrm{a}} 4.5, J_{4-4-\mathrm{OH}} 7.5, J_{4-3 \mathrm{~b}} 12.3 \mathrm{~Hz}, 1 \mathrm{H}\right)$ showed ROESY correlations to $\mathrm{H}-2(\delta$ $2.60, \mathrm{~m}, 1 \mathrm{H})$ and $\mathrm{H}_{3}-13(\delta 0.90, \mathrm{~s}, 3 \mathrm{H})$. Finally, a ROESY correlation observed between $\mathrm{H}_{3}-13$ and $\mathrm{H}_{3}-14(\delta 1.33$, s, $3 \mathrm{H}$ ) (Fig. 3) established the relative configuration at C-8, completing the assignment of the constitution and relative configuration of 1 .

Compound 2 was assigned the same molecular formula as $\mathbf{1}\left(\mathrm{C}_{15} \mathrm{H}_{24} \mathrm{O}_{4}\right)$ on the basis of HRMS (ESI-Q-TOF, $m / z:[\mathrm{M}+\mathrm{Na}]^{+}$calcd for $\mathrm{C}_{15} \mathrm{H}_{24} \mathrm{O}_{4} \mathrm{Na} 291.1572$; found 291.1563 ) data. Its ${ }^{1} \mathrm{H}$ and ${ }^{13} \mathrm{C} \mathrm{NMR}$ data (Tables 1 and 2) were similar to those of 1 , except for the chemical shifts of C-2 $\left(\delta_{\mathrm{H} / \mathrm{C}} 2.91 / 27.4\right)$ and $\mathrm{C}-4\left(\delta_{\mathrm{H} / \mathrm{C}} 4.10 / 71.9\right)$. Furthermore, the H-4 signal exhibited different coupling constants $\left(J_{4-3 \mathrm{a}} 3.6, J_{4-3 \mathrm{~b}} 6.9 \mathrm{~Hz}, 1 \mathrm{H}\right)$ from those observed 


\begin{tabular}{|l|r|r|r|r|r|}
\hline Position & \multicolumn{1}{l}{$\mathbf{l}$} & $\mathbf{2}$ & $\mathbf{3}$ & $\mathbf{4}$ & $\mathbf{5}$ \\
\hline 1 & 141.8 & 141.9 & 139.6 & 203.9 & 203.4 \\
\hline 2 & 31.5 & 27.4 & 31.4 & 38.3 & 43.5 \\
\hline 3 & 36.5 & 37.9 & 42.5 & 42.1 & 43.6 \\
\hline 4 & 69.9 & 71.9 & 69.0 & 62.4 & 68.1 \\
\hline 5 & 83.1 & 83.9 & 62.7 & 170.3 & 174.6 \\
\hline 6 & 44.6 & 45.1 & 40.2 & 46.0 & 47.3 \\
\hline 7 & 53.4 & 54.2 & 55.9 & 51.8 & 52.8 \\
\hline 8 & 47.9 & 47.6 & 49.1 & 50.2 & 50.0 \\
\hline 9 & 164.7 & 166.1 & 169.4 & 140.5 & 140.2 \\
\hline 10 & 197.1 & 195.1 & 195.7 & 15.1 & 15.3 \\
\hline 11 & 20.9 & 20.0 & 21.4 & 30.1 & 30.7 \\
\hline 12 & 23.6 & 22.7 & 24.1 & 28.5 & 29.1 \\
\hline 13 & 26.6 & 27.5 & 30.4 & 23.7 & 23.7 \\
\hline 14 & 30.5 & 30.5 & 30.3 & 69.7 & 70.0 \\
\hline 15 & 71.7 & 71.8 & 72.0 & & \\
\hline & & & & &
\end{tabular}

Table 2. ${ }^{13} \mathrm{C}$ NMR data ( $\delta$ in ppm) of 1-5 (150 MHz; $\left.\mathrm{CD}_{3} \mathrm{OD}\right)$.

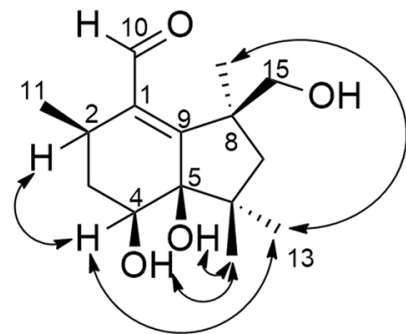

1

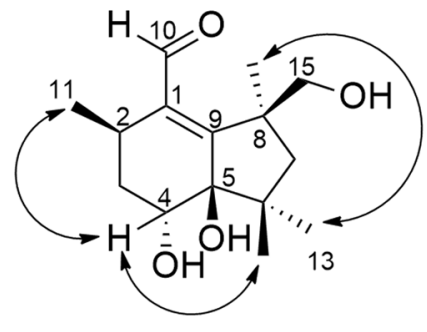

2

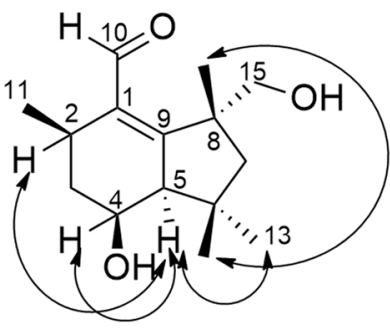

3

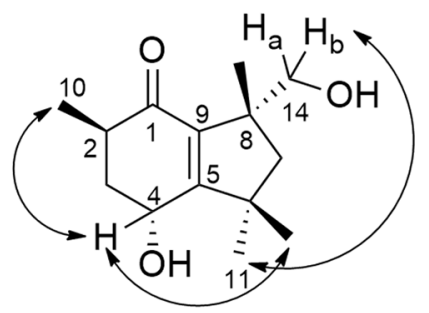

4

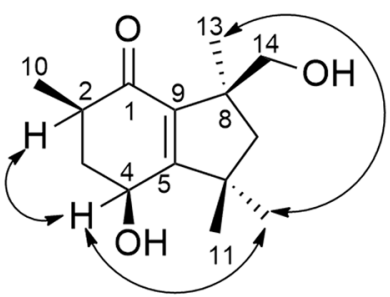

5

Figure 3. ROESY correlations for compound $\mathbf{1}$ and NOESY correlations for compounds 2-5.

for compound $\mathbf{1}$, suggesting that $\mathbf{2}$ was a stereoisomer of $\mathbf{1}$ with a configurational difference at C-4, which was confirmed from 2D NMR data analyses. The HMBC spectrum of 2 (Supplementary Fig. S16) showed correlations of H-10 $(\delta 10.26, \mathrm{~s}, 1 \mathrm{H})$ to $\mathrm{C}-1(141.9)$ and $\mathrm{C}-2$, of $\mathrm{H}-3(\delta 1.80, \mathrm{~m}, 2 \mathrm{H})$ to C-1, C-4 and C-5 $(\delta 83.9)$ (Fig. 2), as observed in compound 1. The relative configuration of 2 was established via 1D NOE experiments (Supplementary Fig. S17). Irradiation of $\mathrm{H}-4$ gave NOEs in $\mathrm{H}_{3}-11\left(\delta 1.05, J_{11-2} 7.2 \mathrm{~Hz}, 3 \mathrm{H}\right)$ and $\mathrm{H}_{3}-12(\delta 1.15, \mathrm{~s}$, $3 \mathrm{H})$ consistent with a cis configuration between $\mathrm{H}-4$ and $\mathrm{H}_{3}-11$, which was different from the cis configuration between $\mathrm{H}-4$ and $\mathrm{H}-2$ in 1 . Irradiation of $\mathrm{H}_{3}-14$ gave an NOE in $\mathrm{H}_{3}-13$ confirming that $\mathrm{C}-8$ had the same relative configuration in both 1 and $\mathbf{2}$ (Fig. 3).

The molecular formula of compound 3 was deduced as $\mathrm{C}_{15} \mathrm{H}_{24} \mathrm{O}_{3}$ from HRMS data (ESI-Q-TOF, $m / z$ : $[\mathrm{M}+\mathrm{Na}]^{+}$calcd for $\mathrm{C}_{15} \mathrm{H}_{24} \mathrm{O}_{3} \mathrm{Na} 275.1623$; found 275.1613). Comparison of the NMR data obtained for 3 (Tables 1 and 2) with those of $\mathbf{1}$ and $\mathbf{2}$ revealed that compound 3 bears a similar structure. However, its ${ }^{1} \mathrm{H}$ NMR spectrum had a double doublet at $\delta 2.33\left(J_{5-2} 3.3, J_{5-4} 8.7 \mathrm{~Hz}, 1 \mathrm{H}\right)$, which was assigned to $\mathrm{H}-5$ after observation of a ${ }^{1} \mathrm{H}-{ }^{1} \mathrm{H}$ COSY correlation to $\mathrm{H}-4\left(\delta 3.62\right.$, ddd, $\left.J_{4-3 \mathrm{a}} 3.9, J_{4-5} 8.7, J_{4-3 \mathrm{~b}} 11.1 \mathrm{~Hz}, 1 \mathrm{H}\right)(\mathrm{Fig} .2)$ and a HSQC correlation to the signal at $\delta 62.7(\mathrm{C}-5)$ (Supplementary Fig. S22). HOMODEC spectrum evidenced its additional coupling to $\mathrm{H}-2(\delta 2.79, \mathrm{~m}, 1 \mathrm{H})$ and confirmed the coupling constant $\left(J_{5-2} 3.3 \mathrm{~Hz}\right)$, upon irradiation of $\mathrm{H}-2$ (Supplementary Fig. S23). The HMBC spectrum (Supplementary Figs S24 and S25) exhibited correlations of $\mathrm{H}_{\mathrm{b}}-7\left(\delta 1.40, \mathrm{~d}, J_{7 \mathrm{~b}-7 \mathrm{a}}\right.$ $13.2 \mathrm{~Hz}, 1 \mathrm{H}), \mathrm{H}_{3}-12(\delta 0.98, \mathrm{~s}, 3 \mathrm{H})$ and $\mathrm{H}_{3}-13(\delta 1.25, \mathrm{~s}, 3 \mathrm{H})$ to $\mathrm{C}-5$ (Fig. 2), coherent with the structure proposed 
for compound 3. NOE experiments disclosed the relative configuration of $\mathbf{3}$ (Supplementary Fig. S26), evidencing the spatial correlation of $\mathrm{H}-4, \mathrm{H}-5, \mathrm{H}-2$ and $\mathrm{H}_{3}-13$ upon irradiation of $\mathrm{H}-5$. The spatial correlation between $\mathrm{H}_{3}-12$ and $\mathrm{H}_{3}-14(\delta 1.44, \mathrm{~s}, 3 \mathrm{H})$ was also observed upon irradiation of $\mathrm{H}_{3}-14$, which indicated the cis stereochemistry between such methyl groups in compound 3 (Fig. 3).

The molecular formula of compound 4 was determined as $\mathrm{C}_{14} \mathrm{H}_{22} \mathrm{O}_{3}$ by HRMS (ESI-TOF, $m / z$ : $[\mathrm{M}+\mathrm{Na}]^{+}$ calcd for $\mathrm{C}_{14} \mathrm{H}_{22} \mathrm{O}_{3} \mathrm{Na} 261.1467$; found 261.1466). Its ${ }^{1} \mathrm{H}$ NMR spectrum (Table 1) revealed the absence of an aldehyde proton, which differs from compounds 1,2 and 3 . On the other hand, its ${ }^{13} \mathrm{C}$ NMR spectrum (Table 2) presented signals at $\delta 203.9$ (C-1), 170.3 (C-5) and 140.5 (C-9), which indicated the presence of an $\alpha, \beta$-unsaturated carbonyl group. Further similarities with compounds 1-3 included the presence of four methyl groups in the ${ }^{1} \mathrm{H}$ NMR (Table 1) and HSQC (Supplementary Fig. S31) spectra, associated to one doublet $\left(\delta 1.10, J_{10-2} 7.2 \mathrm{~Hz}\right.$, $\left.\mathrm{H}_{3}-10\right)$ and three singlets $\left(\delta 1.19 / \mathrm{H}_{3}-13,1.20 / \mathrm{H}_{3}-12\right.$ and $\left.1.32 / \mathrm{H}_{3}-11\right)$, in addition to the signals for one oxymethine hydrogen at $\delta 4.43\left(\mathrm{t}, J_{4-3} 3.0 \mathrm{~Hz}, \mathrm{H}-4\right)$, and two doublets for one hydroxymethylene group at $\delta 3.63$ (d, $\left.J_{14 \mathrm{a}-14 \mathrm{~b}} 10.8 \mathrm{~Hz}, 1 \mathrm{H}, \mathrm{H}_{\mathrm{a}}-14\right)$ and $3.42\left(\mathrm{~d}, J_{14 \mathrm{~b}-14 \mathrm{a}} 10.8 \mathrm{~Hz}, 1 \mathrm{H}, \mathrm{H}_{\mathrm{b}}-14\right)$. The position of the $\alpha, \beta$-unsaturated carbonyl group was deduced from HMBC correlations of $\mathrm{H}_{3}-10$ to $\mathrm{C}-1$, of $\mathrm{H}_{3}-11$ and $\mathrm{H}_{3}-12$ to $\mathrm{C}-5$ and of $\mathrm{H}_{\mathrm{b}}-14$ to C-9 (Fig. 2), which were consistent with the structure of an unprecedented botryane norsesquiterpene carbon skeleton for compound 4. Its relative configuration was established from NOE experiments (Supplementary Fig. S33). Irradiation of $\mathrm{H}_{3}-10$ induced an NOE in $\mathrm{H}-4$, whereas irradiation of $\mathrm{H}-4$ induced an NOE in $\mathrm{H}_{3}-12$, indicating a cis relative configuration among $\mathrm{H}_{3}-10, \mathrm{H}-4$ and $\mathrm{H}_{3}-12$ (Fig. 3). Conversely, the spatial correlation between $\mathrm{H}_{\mathrm{b}}-14$ and $\mathrm{H}_{3}-11$ was observed upon irradiation of $\mathrm{H}_{\mathrm{b}}-14$.

Compound 5 was established as a stereoisomer of 4 , based on the same molecular formula, $\mathrm{C}_{14} \mathrm{H}_{22} \mathrm{O}_{3}$, determined by HRMS (ESI-Q-TOF, $m / z$ : $[\mathrm{M}+\mathrm{H}]^{+}$calcd for $\mathrm{C}_{14} \mathrm{H}_{23} \mathrm{O}_{3} 239.1642$; found 239.1648) in addition to key similarities on their ${ }^{1} \mathrm{H}$ and ${ }^{13} \mathrm{C}$ NMR (Tables 1 and 2$)$ spectra, except for the resonances assigned to $\mathrm{C}-2\left(\delta_{\mathrm{H} / \mathrm{C}}\right.$ $2.43 / 43.5)$ and $\mathrm{C}-4\left(\delta_{\mathrm{H} / \mathrm{C}} 4.69 / 68.1\right)$, and coupling constants for the $\mathrm{H}-4$ signal $\left(J_{4-3 \mathrm{a}} 4.8, J_{4-3 \mathrm{~b}} 10.2\right)$. The HMBC spectrum (Supplementary Fig. S39) showed correlations of $\mathrm{H}_{3}-10\left(\delta 1.10, \mathrm{~d}, J_{10-2} 6.6,3 \mathrm{H}\right)$ to $\mathrm{C}-1$ ( $(\delta 203.4)$, of $\mathrm{H}_{3}-11(\delta 1.38, \mathrm{~s}, 3 \mathrm{H})$ and $\mathrm{H}_{3}-12(\delta 1.31, \mathrm{~s}, 3 \mathrm{H})$ to $\mathrm{C}-5(\delta 174.6)$, and of $\mathrm{H}_{\mathrm{b}}-14\left(\delta 3.54, \mathrm{~d}, J_{14 \mathrm{~b}-14 \mathrm{a}} 10.8,1 \mathrm{H}\right)$ to $\mathrm{C}-9(\delta$ 140.2) (Fig. 2), which are associated with an $\alpha, \beta$-unsaturated carbonyl moiety as in compound 4 . Similar results from NOE experiments corroborated the proposed relative configuration for 5 (Supplementary Fig. S40), including the observation of NOEs among $\mathrm{H}-4, \mathrm{H}_{3}-12$ and $\mathrm{H}_{3}-13(\delta 1.13, \mathrm{~s}, 3 \mathrm{H})$ upon irradiation of $\mathrm{H}_{3}-12$, as well as between $\mathrm{H}-4$ and $\mathrm{H}-2(\delta 2.43, \mathrm{~m})$, upon irradiation of $\mathrm{H}-4$, which is consistent with a cis relative configuration among $\mathrm{H}-4, \mathrm{H}-2, \mathrm{H}_{3}-12$ and $\mathrm{H}_{3}-13$. Such data differentiate compound 5 from 4 , which presented a cis configuration between $\mathrm{H}-4$ and $\mathrm{H}_{3}-10$ (Fig. 3).

It is worth noting the high chemical shift of C-9 for compounds 1-3 and for C-5 in case of compounds 4 and 5, which are consistent with the $\beta$-carbon shift of $\alpha, \beta$-unsaturated carbonyl moieties ${ }^{16,17}$.

Compound 6 was identified as $4 \beta$-Acetoxy-9 $9 \beta, 10 \beta, 15 \alpha$-trihydroxyprobotrydial, based on NMR and HRMS data, and comparison with those reported in the literature ${ }^{18}$.

Due to the amount of sample available, VCD was used for the absolute configuration assignments of compounds 1 and 5 only, while ECD was carried out for compounds 2-4. Regarding compounds $\mathbf{1}$ and 5, the similarity between observed and density functional theory (DFT) predicted IR/VCD spectra, at the B3LYP/PCM(MeOH)/6-31G(d) level, led to the unambiguous assignment of their absolute configuration as $(+)-(2 R, 4 S, 5 R, 8 S)-\mathbf{1}$ and $(+)-(2 R, 4 S, 8 S)-5$ (Fig. 4$)$. In line with previous results from our group ${ }^{19}$, the agreement between theoretical and observed data in methanol- $d_{4}$ solution was greatly improved by considering deuterated hydroxyl groups for the calculations. As for compounds 2-4, the correlation of experimental and time-dependent DFT (TD-DFT) simulated ECD spectra, at the CAM-B3LYP/PCM $(\mathrm{MeOH}) / \mathrm{TZVP}$ level, allowed the determination of their absolute configuration as $(+)-(2 R, 4 R, 5 R, 8 S)-\mathbf{2},(+)-(2 R, 4 S, 5 R, 8 R)-\mathbf{3}$, and (+) $-(2 R, 4 R, 8 R)-\mathbf{4}$ (Fig. 5).

In the specific case of compound 2, DFT and TD-DFT calculations were carried out for both configurations possible at C-5, as its relative configuration were not readily available from NMR data. As a result, the best agreement between experimental and calculated UV/ECD data was observed for $2 R, 4 R, 5 R, 8 S-2$ (Fig. 5 and Supplementary Figs S46 and S47).

Compounds 1-3 are structurally related to botryenalol, previously isolated from Botrytis cinerea, a phytopathogenic ascomycete found in grapes in a Domecq vineyard, Jerez de La Frontera, Cádiz ${ }^{16}$. However, these compounds have different substituents, especially compounds $\mathbf{1}$ and $\mathbf{2}$, which bear a hydroxy group on carbon 5 , a structural feature not described yet for botryane terpenoids.

Biogenetically, botryane derivatives have farnesyldiphosphate (FPP) as a precursor, and the key intermediate $\mathbf{A}$ is generated after cyclization, rearrangement, and hydroxylation. Subsequent hydroxylation and acetylation reactions could transform A to $4 \beta$-acetoxy-9 $\beta, 10 \beta, 15 \alpha$-trihydroxyprobotrydial (6), an intermediate in the biosynthesis of botrydial and its derivatives ${ }^{20,21}$. Further steps in the biogenetic proposal include cleavage of the vicinal diol in $\mathbf{A}$ to give the dialdehyde $\mathbf{B}$ followed by reduction, dehydration, and hydroxylation to generate $\mathbf{1}$ and $\mathbf{2}$. As suggested by Collado et al., a retro Aldol reaction might epimerize C-8 to give intermediate $\mathbf{C}^{21}$. Reduction, dehydration, and hydroxylation can convert intermediate $\mathbf{C}$ into $\mathbf{3}$ and intermediate $\mathbf{D}$. Allylic rearrangement and oxidative decarboxylation would convert $\mathbf{1}$ into $\mathbf{5}$ and $\mathbf{D}$ into $\mathbf{4}$, the two new N. bipapillata metabolites with unprecedented rearranged and degraded terpenoid carbon skeletons (Fig. 6).

Some bothryane derivatives showed phytotoxic effects ${ }^{18}$, as well as antibacterial and cytotoxic activities ${ }^{13,21,22}$. Botryane metabolites were also previously described from marine microorganisms, including a fungal strain of Geniculosporium sp. isolated from the red alga Polysiphonia sp., which afforded eleven new botryane terpenoids with algicidal, antibacterial and fungicidal activity against Chlorella fusca, Bacillus megaterium and Microbotryum violaceum, respectively ${ }^{17}$. Furthermore, the first botrydiol-coumarin hybrid, hypocrolide $\mathrm{A}^{23}$, and novel heterodimeric botryane ethers ${ }^{24}$ were isolated from Hypocrea sp., an insect-associated fungus, isolated from a Septobasidium-infected insect, Serrataspis sp. 

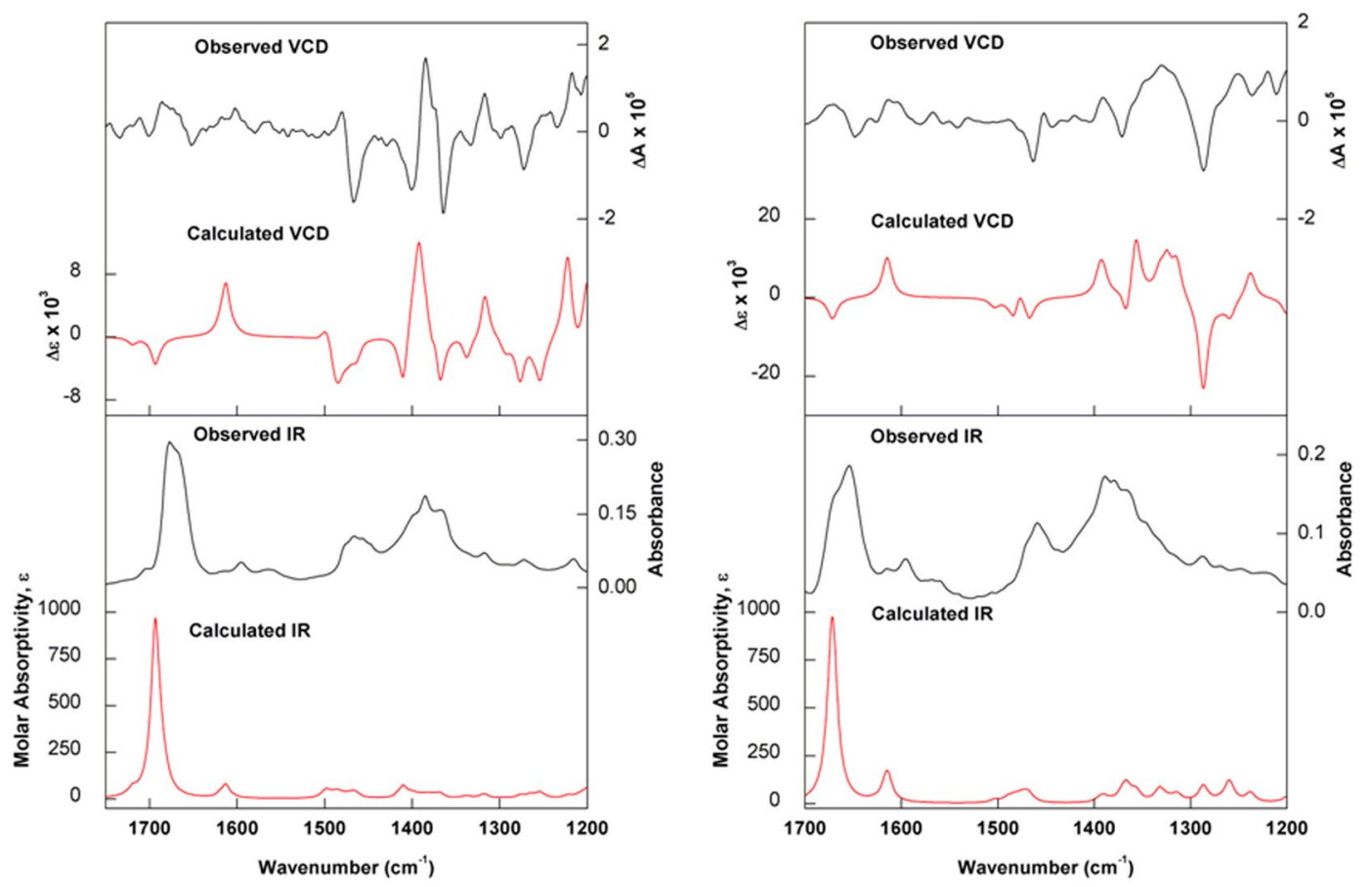

Figure 4. (Left) Experimental and calculated $[2 R, 4 S, 5 R, 8 S$; B3LYP/PCM $(\mathrm{MeOH}) / 6-31 \mathrm{G}(\mathrm{d})]$ IR and VCD spectra of (+)-1. (Right) Experimental and calculated [2R,4S,8S; B3LYP/PCM(MeOH)/6-31G(d)] IR and VCD spectra of $(+)$-5. For structures of the lowest-energy conformers, please see Supplementary Information.

The isolated metabolites 1-6 were tested for their ability to inhibit cholinesterase (ChEIs) (Table 3). The inhibition assays were carried out using an immobilized capillary enzyme reactor (ICER) based on acetylcholinesterase human recombinant and/or butyrylcholinesterase from human serum, respectively huAChE-ICER and $h u$ BChE-ICER (in accordance with published procedure) ${ }^{25-27}$. Compounds 2-6 were more active towards $h u \mathrm{AChE}$ than $h u \mathrm{BChE}$, indicating a selective cholinesterase inhibition, and $\mathbf{4}$ was the most active compound, with $27.7 \%(100 \mu \mathrm{M})$ inhibition against $h u A C h E$. Compound 1 was considered a non-selective inhibitor, as it showed similar inhibitory potentials against both $h u \mathrm{AChE}$ and $h u \mathrm{BChE}(19.9$ and $14.1 \%$, respectively), while its stereoisomer (compound 2) inhibited only huAChE (18.3\%). The results represent only modest inhibition of $h u \mathrm{AChE}$ or $h u \mathrm{BChE}$, but they suggest that botryane terpenoids could act as lead compounds for synthetic development of more potent selective cholinesterase ligands.

Compounds 1, 3, 5 and $\mathbf{6}$ were tested against colorectal carcinoma HCT-116 and breast adenocarcinoma MCF-7 cell lines using the 3-(4,5-dimethylthiazol-2-yl)-2,5-diphenyltetrazolium bromide tetrazolium reduction $(\mathrm{MTT})$ assay, and presented no significant toxicixity at tested concentrations $\left(\mathrm{IC}_{50}>50 \mu \mathrm{M}\right)$ against both cell lines. Previous studies have shown that the presence of the 1,5-dialdehyde moiety, as in botrydial, is an important structural feature for cytotoxicity, including the $S$ configuration at $\mathrm{C}-1^{13,21}$. Our results corroborate previous findings as compounds 1, 3, $\mathbf{5}$ and $\mathbf{6}$ do not bear the 1,5-dialdehyde unit, which possibly resulted in the lack of cytotoxic activity. In addition, $\mathrm{C}-1$ in compounds $\mathbf{1 , 3}$ and $\mathbf{5}$ is an $\mathrm{sp}^{2}$ carbon as part of $\alpha, \beta$-unsaturated carbonyl system and therefore the $S$ configuration at $\mathrm{C}-1$ requirement is also not met.

In summary, this study expands the known chemodiversity of marine microorganisms, since it is the first to describe the isolation of metabolites from a fungal strain of Nemania bipapillata, as well as the occurrence of botryane terpenoids in this genus. Compounds 1-5 are new members of the botryane family, highlighting compounds 4 and 5, which bear a new norsesquiterpene skeleton and were named in accordance with structural functions and the genus Nemania. ECD and VCD quantum chemical calculations were essential techniques to determine the absolute configuration of this class of compounds since there were no studies of similar compounds in the literature to be used as models. The cholinesterase inhibitory activities of compounds $\mathbf{1}$ and $\mathbf{2}$, although relatively modest in potency, suggest that they may be lead structures for developing more potent analogs.

\section{Methods}

General experimental procedure. Optical rotations were determined with a Polartronic H (Schmidt + Haensch) spectrometer. UV spectra were recorded with a Perkin Elmer Lambda 1050 spectrophotometer. ECD and UV spectra were recorded in methanol using a JASCO J-815 spectrometer. Parameters were set as follows: band width $1 \mathrm{~nm}$; response $1 \mathrm{sec}$; scanning speed $100 \mathrm{~nm} \mathrm{~min}^{-1} ; 3$ accumulations; room temperature; $0.1 \mathrm{~cm}$ path lentgh cell; concentration $0.3-0.5 \mathrm{mg} \mathrm{mL}^{-1}$. IR and VCD spectra of compounds 1 and 5 were measured simultaneously with a ChiralIR-2X FT-VCD spectrometer (BioTools) equipped with a single photoelastic modulator $(\mathrm{PEM})$ at a resolution of $4 \mathrm{~cm}^{-1}$ for $8 \mathrm{~h}$. The optimum retardation of the $\mathrm{ZnSe} P E M$ was set at $1400 \mathrm{~cm}^{-1}$. Baselines were corrected by subtracting the VCD spectrum of compounds $\mathbf{1}$ and $\mathbf{5}$ from that obtained for the solvent. 

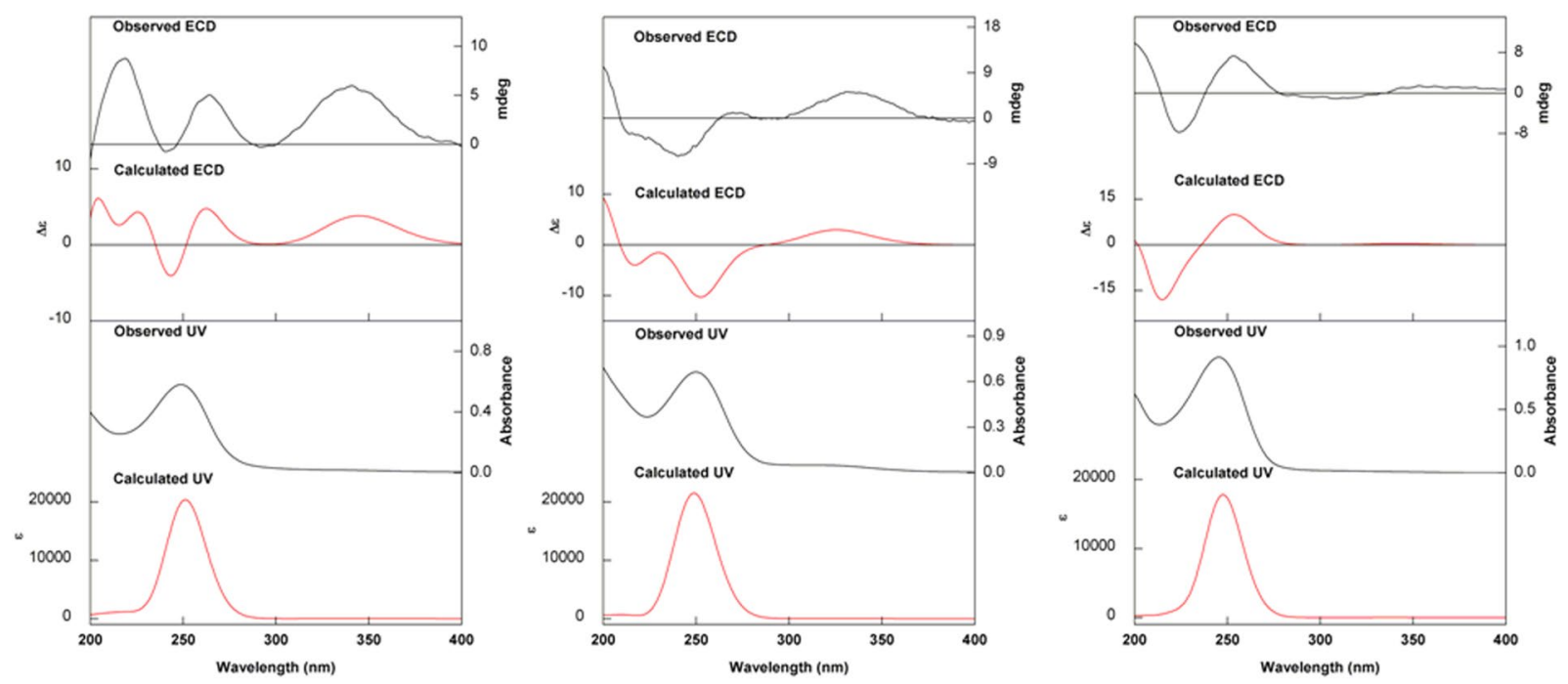

Figure 5. (Left) Experimental and calculated $[2 R, 4 R, 5 R, 8 S$; CAM-B $3 \mathrm{LYP} / \mathrm{PCM}(\mathrm{MeOH}) / \mathrm{TZVP} / / \mathrm{B} 3 \mathrm{LYP} /$ $\operatorname{PCM}(\mathrm{MeOH}) / 6-31 \mathrm{G}(\mathrm{d})] \mathrm{UV}$ and ECD spectra of $(+)-2$ (Center) Experimental and calculated $[2 R, 4 S, 5 R, 8 R$; CAM-B3LYP/PCM(MeOH)/TZVP//B3LYP/PCM(MeOH)/6-31G(d)] UV and ECD spectra of (+)-3 (Right) Experimental and calculated $[2 R, 4 R, 8 R$; CAM-B3LYP/PCM $(\mathrm{MeOH}) / \mathrm{TZVP} / / \mathrm{B} 3 \mathrm{LYP} / \mathrm{PCM}(\mathrm{MeOH}) / 6-31 \mathrm{G}(\mathrm{d})]$ $\mathrm{UV}$ and ECD spectra of (+)-4. For structures of the lowest-energy conformers, please see Supplementary Information.

Vibrational chiroptical spectra were measured in $\mathrm{BaF}_{2}$ cell with $100 \mu \mathrm{m}$ path length in methanol- $d_{4}$. Samples concentration: compound $1,4 \mathrm{mg} / 120 \mu \mathrm{L}$ of $\mathrm{CD}_{3} \mathrm{OD}$, compound $5,3 \mathrm{mg} / 120 \mu \mathrm{L}$ of $\mathrm{CD}_{3} \mathrm{OD}$. $1 \mathrm{D}$ and $2 \mathrm{D}$ NMR experiments were recorded on Bruker Avance III HD 600 and Bruker Avance $600(14,1 \mathrm{~T})$ spectrometers with a $5 \mathrm{~mm}$ TCI cryoprobe. Chemical shifts were reported in $\delta(\mathrm{ppm})$ and were referenced to the residual DMSO- $d_{6}$ and $\mathrm{CD}_{3} \mathrm{OD}$ ( $\delta 2.49$ and 3.31, respectively, for ${ }^{1} \mathrm{H}$ chemical shifts; $\delta 39.5$ and 49.0 for ${ }^{13} \mathrm{C}$ chemical shifts). High resolution ESI-TOF and ESI-Q-TOF-MS were recorded with Waters/Micromass LCT and Bruker Maxix Impact spectrometers, respectively. Semi-preparative HPLC was performed on a Shimadzu equipment containing two pumps LC-6AD, a SPD-M20A photodiode array detector and a system controller CBM-20A, and using a C-18 (2) Phenomenex Luna $(250 \times 10 \mathrm{~mm} ; 5 \mu \mathrm{m} ; 100 \AA)$ column and HPLC grade solvents. Chromatography analyses were carried out using reversed phase silica column (C-18, 40-75 $\mu \mathrm{m}, 60 \AA$ A ; Sorbent Technologies). Silica gel plates on aluminum (silica gel $60 \mathrm{~F}_{254}$-Merck) were used for analytical thin layer chromatography (TLC).

Collection of alga. Asparagopsis taxiformis (Falkenbergia stage) specimens were collected at the rocky shore of Fortaleza Beach (Ubatuba, SP, Brazil, GPS: $23^{\circ} 21^{\prime} 38^{\prime \prime} \mathrm{S}, 44^{\circ} 49^{\prime} 63^{\prime \prime} \mathrm{W}$ ), in June 2013. A voucher specimen (SP 428533) was deposited in the herbarium of the Institute of Botany (SMA/SP). After washing carefully with seawater, the algal specimens were kept in previously prepared flasks containing sterile seawater and antibiotic chloramphenicol $\left(200 \mathrm{mg} \mathrm{L}^{-1}\right)$.

Fungal material. Algal specimens were immersed in a $1 \% \mathrm{NaOCl}$ solution (v/v) during 6 seconds and $70 \%$ ethanol solution (v/v) during 2 seconds, followed by seawater rinsing as a surface sterilization procedure. Then, each alga was fragmented and small pieces were spread on PDA (potato, dextrose and agar) plates prepared with sterilized seawater containing the antibiotic chloramphenicol $\left(200 \mathrm{mg} \mathrm{L}^{-1}\right)$. A fungal strain codified as AT-05 was isolated after successive replication in PDA plates. Total DNA was extracted using fresh mycelium with an extraction kit (ZR Fungal/Bacterial DNA MicroPrep) following the manufacturer's recommendations. Molecular identification was carried out by sequencing of ITS (primers ITS1 and ITS4) ${ }^{28}$. The amplicons were enzymatically purified (Agencourt AMPure XP, Beckman Coulter Inc.) and sequenced by the Sanger method (BigDye Terminator v.3.1 Cycle Sequencing). The obtained sequences were uploaded to Genbank database ${ }^{29}$ (accession number MH025760) and the comparison with sequences from the GenBank database was carried out using the nBLAST tool. The fungal strain was identified as Nemania bipapillata ${ }^{30}$. Voucher specimen was deposited at the Endophytic Fungi Collection in our laboratory.

Fermentation, extraction and isolation. Small agar slices bearing mycelia of the AT-05 strain were transferred to 15 Erlenmeyer flasks $(500 \mathrm{~mL}$ ) containing $300 \mathrm{~mL}$ of PDB (potato, dextrose broth) medium prepared with deionized water and incubated for 28 days at $25^{\circ} \mathrm{C}$. Thereafter, the medium was separated from the mycelium by filtration and extracted with EtOAc $(3 \times 50 \%$ of each medium volume). Evaporation of EtOAc yielded $1.74 \mathrm{~g}$ of AT- 05 crude extract.

An aliquot of AT-05 crude extract $(1.51 \mathrm{~g})$ was fractionated on a C-18 derivatized silica column ( $150 \mathrm{~g}$, $\Phi=3.5 \mathrm{~cm})$ using $\mathrm{MeOH}: \mathrm{H}_{2} \mathrm{O}$ gradient $(1: 1,60: 40,75: 25,100: 0)$ as eluent and yielded 4 fractions $(360 \mathrm{~mL}$ each; AT-05-F1 - AT-05-F4). Fraction AT-05-F2 $(200 \mathrm{mg})$ was chromatographed by semi-preparative HPLC using a linear gradient (30 to $80 \% \mathrm{MeOH}: \mathrm{H}_{2} \mathrm{O}$ ) for 40 minutes and a flow rate of $4.5 \mathrm{~mL} \mathrm{~min}^{-1}$, which afforded compounds 1 


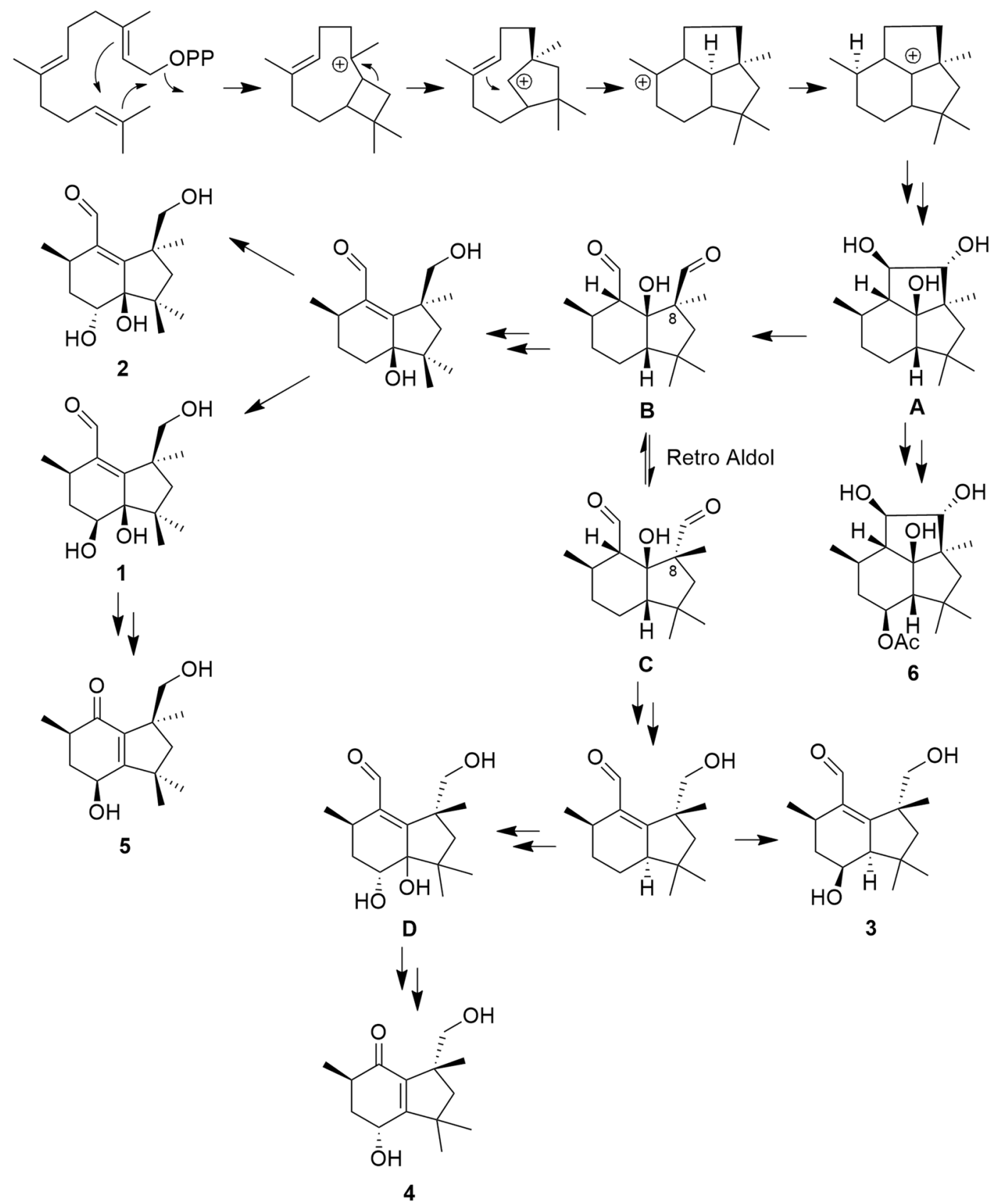

Figure 6. Biogenetic proposal for compounds 1-6.

\begin{tabular}{|l|l|l|}
\hline Samples & $\begin{array}{l}\text { \% inhibition } \\
\boldsymbol{h u \text { AChE- }} \\
\text { ICER } \pm \text { SEM }\end{array}$ & $\begin{array}{l}\text { \% inhibition } \\
\boldsymbol{h} u \text { BChE- } \\
\text { ICER } \pm \text { SEM }\end{array}$ \\
\hline Galanthamine & $90.7 \pm 0.0$ & $82.0 \pm 0.2$ \\
\hline $\mathbf{1}$ & $19.9 \pm 1.7$ & $14.1 \pm 1.7$ \\
\hline $\mathbf{2}$ & $18.3 \pm 1.8$ & $6.7 \pm 0.7$ \\
\hline $\mathbf{3}$ & $21.1 \pm 0.1$ & $5.5 \pm 1.5$ \\
\hline $\mathbf{4}$ & $27.7 \pm 1.3$ & $7.3 \pm 1.5$ \\
\hline $\mathbf{5}$ & $22.8 \pm 0.8$ & $5.1 \pm 0.0$ \\
\hline $\mathbf{6}$ & $19.6 \pm 2.7$ & $3.2 \pm 1.5$ \\
\hline
\end{tabular}

Table 3. Inhibition of $h u A C h E-I C E R$ and $h u B C h E-I C E R$ activities by galanthamine (positive control; $100 \mu \mathrm{M}$ )

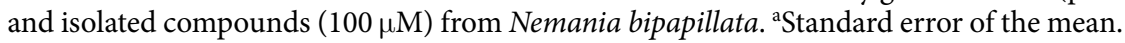


$\left(t_{R} 23.5 \mathrm{~min} ; 5.8 \mathrm{mg}\right), 2\left(t_{R} 21.1 \mathrm{~min} ; 1.0 \mathrm{mg}\right), 3\left(t_{\mathrm{R}} 25.0 \mathrm{~min} ; 3.0 \mathrm{mg}\right), 4\left(\mathrm{t}_{\mathrm{R}} 21.9 \mathrm{~min} ; 1.4 \mathrm{mg}\right), 5\left(\mathrm{t}_{\mathrm{R}} 27.3 \mathrm{~min} ; 3.6 \mathrm{mg}\right)$ and $\mathbf{6}\left(\mathrm{t}_{\mathrm{R}} 26.4 \mathrm{~min} ; 13.8 \mathrm{mg}\right)$.

$(+)-(2 R, 4 S, 5 R, 8 S)$-4-deacetyl-5-hydroxy-botryenalol (1): colorless oil; $[\alpha]_{\mathrm{D}}{ }^{23}+55.9$ (c 0.2, $\left.\mathrm{MeOH}\right) ; \mathrm{UV}$ $(\mathrm{MeOH}) \lambda_{\max }(\log \varepsilon) 248 \mathrm{~nm}(3.80) ; \mathrm{CD}\left(\mathrm{MeOH}, 1.86 \mathrm{mmol} \mathrm{L}^{-1}\right) \lambda_{\text {ext }}(\Delta \varepsilon) 337(+2.11), 246(-2.87), 206 \mathrm{~nm}$ $(+4.59) ;{ }^{1} \mathrm{H}$ NMR data see Table $1 ;{ }^{13} \mathrm{C}$ NMR data see Table 2; HRMS (ESI-TOF) $m / z$ : $[\mathrm{M}+\mathrm{Na}]^{+}$calcd for $\mathrm{C}_{15} \mathrm{H}_{24} \mathrm{O}_{4} \mathrm{Na} 291.1572$; found 291.1576.

$(+)-(2 R, 4 R, 5 R, 8 S)$-4-deacetyl-5-hydroxy-botryenalol (2): colorless oil; $[\alpha]_{\mathrm{D}}{ }^{23}+33.7$ (c 0.13, MeOH); UV $(\mathrm{MeOH}) \lambda_{\max }(\log \varepsilon) 249 \mathrm{~nm}(3.01) ; \mathrm{CD}\left(\mathrm{MeOH}, 1.86 \mathrm{mmol} \mathrm{L}^{-1}\right) \lambda_{\text {ext }}(\Delta \varepsilon) 341(+0.97), 264(+0.82), 220 \mathrm{~nm}$ $(+1.43) ;{ }^{1} \mathrm{H}$ NMR data: see Table $1 ;{ }^{13} \mathrm{C}$ NMR data: see Table 2; HRMS (ESI-Q-TOF) $\mathrm{m} / z:[\mathrm{M}+\mathrm{Na}]^{+}$calcd for $\mathrm{C}_{15} \mathrm{H}_{24} \mathrm{O}_{4} \mathrm{Na} 291.1572$; found 291.1563.

$(+)-(2 R, 4 S, 5 R, 8 R)$-4-deacetyl-botryenalol (3): colorless oil; $[\alpha]_{\mathrm{D}}{ }^{23}+22.2(c 0.2, \mathrm{MeOH}) ; \mathrm{UV}(\mathrm{MeOH}) \lambda_{\max }$ $(\log \varepsilon) 250 \mathrm{~nm}$ (3.49); $\mathrm{CD}\left(\mathrm{MeOH}, 1.98 \mathrm{mmol} \mathrm{L}^{-1}\right) \lambda_{\text {ext }}(\Delta \varepsilon) 330(+0.91), 270(+0.29), 237 \mathrm{~nm}(-0.93) ;{ }^{1} \mathrm{H}$ NMR data see Table $1 ;{ }^{13} \mathrm{C}$ NMR data see Table 2; HRMS (ESI-Q-TOF) $m / z$ : $[\mathrm{M}+\mathrm{Na}]^{+}$calcd for $\mathrm{C}_{15} \mathrm{H}_{24} \mathrm{O}_{3} \mathrm{Na} 275.1623$; found 275.1613 .

Nemenonediol A $[(+)-(2 R, 4 R, 8 R)-4]$ : colorless oil; $[\alpha]_{\mathrm{D}}{ }^{23}+6.86(c 0.14, \mathrm{MeOH}) ; \mathrm{UV}(\mathrm{MeOH}) \lambda_{\max }(\log$ ع) $246 \mathrm{~nm}$ (3.77); CD (MeOH, $\left.1.26 \mathrm{mmol} \mathrm{L}^{-1}\right) \lambda_{\text {ext }}(\Delta \varepsilon) 309(-0.40), 253(+1.67), 224(-1.93) ;{ }^{1} \mathrm{H}$ NMR data see Table $1 ;{ }^{13} \mathrm{C}$ NMR data see Table 2; HRMS (ESI-TOF) $m / z$ : $[\mathrm{M}+\mathrm{Na}]^{+}$calcd for $\mathrm{C}_{14} \mathrm{H}_{22} \mathrm{O}_{3} \mathrm{Na}$ 261.1467; found 261.1466. IUPAC nomenclature: $(3 R, 5 R, 7 R)-7$-hydroxy-3-(hydroxymethyl)-1,1,3,5-tetramethyl2,3,6,7-tetrahydro- $1 \mathrm{H}$-inden-4 $(5 \mathrm{H})$-one.

Nemenonediol B $[(+)-(2 R, 4 S, 8 S)-5]$ : colorless oil; $[\alpha]_{\mathrm{D}}^{23}+8.6(c 0.2, \mathrm{MeOH}) ; \mathrm{UV}(\mathrm{MeOH}) \lambda_{\max }(\log \varepsilon) 247 \mathrm{~nm}$ (3.65); $\mathrm{CD}\left(\mathrm{MeOH}, 2.10 \mathrm{mmol} \mathrm{L}^{-1}\right) \lambda_{\text {ext }}(\Delta \varepsilon) 251(-4.06), 215 \mathrm{~nm}(+6.09) ;{ }^{1} \mathrm{H}$ NMR data see Table $1 ;{ }^{13} \mathrm{C}$ NMR data see Table 2; HRMS (ESI-Q-TOF) $m / z$ : $[\mathrm{M}+\mathrm{H}]^{+}$calcd for $\mathrm{C}_{14} \mathrm{H}_{23} \mathrm{O}_{3}$ 239.1642; found 239.1648. IUPAC nomenclature: (3S,5R,7S)-7-hydroxy-3-(hydroxymethyl)-1,1,3,5-tetramethyl-2,3,6,7-tetrahydro- $1 \mathrm{H}$-inden-4(5H)-one.

$4 \beta$-Acetoxy-9 $3,10 \beta, 15 \alpha$-trihydroxyprobotrydial (6): colorless oil; ${ }^{1} \mathrm{H}$ NMR and ${ }^{13} \mathrm{C}$ NMR data were consistent with those previously reported ${ }^{18}$; HRMS (ESI-Q-TOF) $m / z$ : $[\mathrm{M}+\mathrm{Na}]^{+}$calcd for $\mathrm{C}_{17} \mathrm{H}_{28} \mathrm{O}_{5} \mathrm{Na} 335.1834$; found 335.1828 .

Calculations. This section was adapted from previously published methods ${ }^{19,31}$. All DFT simulations were carried using Gaussian 09 software ${ }^{32}$. Solvation in methanol was treated implicitly using the polarizable continuum model (PCM) in its integral equation formalism version (IEFPCM). For the calculations, the following configurations were arbitrarily chosen: $(2 R, 4 S, 5 R, 8 S)-\mathbf{1} ;(2 R, 4 R, 5 S, 8 S)$ - and $(2 R, 4 R, 5 R, 8 S)-\mathbf{2} ;(2 R, 4 S, 5 R, 8 R)-\mathbf{3}$; $(2 R, 4 R, 8 R)-4$; and $(2 R, 4 S, 8 S)-5$. Conformational searches were performed using molecular mechanics with the Monte Carlo algorithm and $\mathrm{MM}+$ force field available in HyperChem 8.0.10 software package. For $(2 R, 4 S, 5 R, 8 S)-1,10$ conformers with relative energy (rel E.) within $6 \mathrm{kcal} \mathrm{mol}^{-1}$ were selected and had their geometry optimized at the B3LYP/PCM $(\mathrm{MeOH}) / 6-31 \mathrm{G}^{*}$ level. The five conformers with rel E. $<2.0 \mathrm{kcal} \mathrm{mol}^{-1}$ ( $>98 \%$ of the total Boltzmann distribution) were selected for IR and VCD spectral calculations. Regarding $(2 R, 4 R, 5 S, 8 S)$ - and $(2 R, 4 R, 5 R, 8 S)-2,2$ conformers each, with rel E. within $6 \mathrm{kcal} \mathrm{mol}^{-1}$ were selected and had their geometry optimized at the B3LYP/PCM $(\mathrm{MeOH}) / 6-31 \mathrm{G}^{*}$ level. One and two conformers, respectively (rel E. $\left.<2.0 \mathrm{kcal} \mathrm{mol}^{-1}\right)$ were used for UV and ECD spectral calculations. For $(2 R, 4 S, 5 R, 8 R)-3,8$ conformers (rel E. within $6 \mathrm{kcal} \mathrm{mol}^{-1}$ ) were selected and had their geometry optimized at the B3LYP/PCM(MeOH)/6-31G* level. Two conformers with rel E. $<2.0 \mathrm{kcal} \mathrm{mol}^{-1}$ were used during UV and ECD spectral calculations. In the case of $(2 R, 4 R, 8 R)-4,2$ conformers (rel E. within $6 \mathrm{kcal} \mathrm{mol}^{-1}$ ) were selected and had their geometry optimized at the B3LYP/PCM(MeOH)/6-31G* level. These two conformations (rel E. $<2.0 \mathrm{kcal} \mathrm{mol}^{-1}$ ) were selected for UV and ECD spectral calculations. For $(2 R, 4 S, 8 S)-5,2$ conformations (rel E. within $6 \mathrm{kcal} \mathrm{mol}^{-1}$ ) were selected and had their geometry optimized at the B3LYP/PCM $(\mathrm{MeOH}) / 6-31 \mathrm{G}^{*}$ level. These same conformers were used for IR and VCD calculations. Replacement of some hydrogen atoms with deuterium atoms was performed using GaussView 5.0.9 software for the same conformer population identified for each configuration. Dipole and rotational strengths were used to create IR and VCD spectra, in $\mathrm{M}^{-1} \mathrm{~cm}^{-1}$ units, These quantities were calculated at the same level of theory used during geometry optimization. Spectra were plotted as a sum of Lorentzian bands with $\mathrm{HWHM}$ of $6 \mathrm{~cm}^{-1}$. The calculated wavenumbers were multiplied with a scaling factor of 0.975 . The final spectra were generated as Boltzmann averages of the lowest-energy conformers identified and plotted using Origin8 software. No imaginary frequencies were obtained after vibrational analysis at the B3LYP/PCM $(\mathrm{MeOH}) / 6-31 \mathrm{G}^{*}$ level thus confirming the considered conformers as real minima. Subsequently, TD-DFT was used to calculate excitation energies (in $\mathrm{nm}$ ) and rotatory strengths $(R)$ in dipole velocity form $\left(R_{\mathrm{vel}}\right.$ in cgs units: $\left.10^{-40} \mathrm{esu}^{2} \mathrm{~cm}^{2}\right)$, at the CAM-B3LYP/PCM $(\mathrm{MeOH}) / \mathrm{TZVP}$ level. The calculated rotatory strengths from the first 30 singlet $\rightarrow$ singlet electronic transitions were simulated into an ECD curve using Gaussian bands with bandwidth $\sigma 0.25 \mathrm{eV}$. Calculated wavelength transitions were multiplied with a scaling factor of 1.04, which was determined based on the agreement between experimental and calculated UV data. The final spectra were generated as simple averages of the lowest-energy conformers and plotted using Origin8 software.

Cholinesterase inhibition screening assays. Test samples were submitted to a punctual cholinesterase inhibition screening assay. $h u \mathrm{AChE}$ and $h u \mathrm{BChE}$ were immobilized independently onto fused silica capillary $(0.1 \mathrm{~mm}$ I.D $\times 0.375 \mathrm{~mm} \times 30 \mathrm{~cm})$ using glutaraldehyde as spacer $(h u A C h E-I C E R \text { and } h u B C h E-I C E R)^{26,27}$.

$h u$ AChE-ICER and $h u$ BChE-ICER were interfaced to the LC-IT-MS/MS as alow affinity and high selectivity biochromatography column. The LC system (Nexera, Shimadzu) consisted of two LC-20AD pumps, a SIL20A autosampler with a $50 \mu \mathrm{L}$ loop, a DGU-20A5 degasser and a CBM-20A interface. The LC system was coupled to an Amazon Speed Ion Trap (IT) mass spectrometer (Bruker Daltonics) equipped with an ESI source, operating in a positive mode (scan $50-250 \mathrm{~m} / \mathrm{z}$ ). Data acquisition was carried out using the Bruker Data Analysis Software 
(version 4.3). All analyses were performed at room temperature $\left(21^{\circ} \mathrm{C}\right)$. The enzymatic reaction was monitored by direct quantification of acetylcholine hydrolysis product, $\mathrm{Ch}\left(\mathrm{m} / \mathrm{z}:[\mathrm{M}+\mathrm{H}]^{+} 104.17\right)^{26,27}$.

$2 \mathrm{U} \mathrm{mL}^{-1}$ of $h u \mathrm{AChE}$ and $0.5 \mathrm{U} \mathrm{mL}^{-1}$ of $h u \mathrm{BChE}$ were immobilized and the apparent kinetic constant $\left(\mathrm{K}_{\text {Mapp }}=70 \mu \mathrm{M}\right)$ was obtained independently using acetylcholine $(\mathrm{ACh})$ as substrate by varying the substrate concentration while measuring the $\mathrm{Ch}[\mathrm{M}+\mathrm{H}]^{+} 104.17 \mathrm{~m} / z$ formation. GraphPad Prism 5 software was used to obtain Michaelis-Menten plots by nonlinear regression analysis ${ }^{27}$.

Ammonium acetate solution $(15 \mathrm{mM}, \mathrm{pH} 8.0)$ was used as running buffer at a flow rate of $50 \mu \mathrm{L} \mathrm{min}{ }^{-1}$ and a second pump delivered methanol after the $h u$ BChE-ICER or $h u$ AChE-ICER and before the IT-MS throughout a " $\mathrm{T}$ " shaped connection, at the same flow rate as the running buffer. Total analysis time was $3 \mathrm{~min}$. IT-MS parameters were: $4.000 \mathrm{~V}$ capillary voltage, $500 \mathrm{~V}$ end plate voltage, $8.0 \mathrm{Lmin}^{-1}$ drying gas, $275^{\circ} \mathrm{C}$ drying temperature and 35 psi nebulizer. Isolation width was set at $\pm m / z$. 0.5 . Fragmentation amplitude was set to $120 \%$. Nitrogen was used as sheath gas and helium as collision gas ${ }^{27}$.

Galanthamine was used as standard cholinesterase inhibitor. Methanol stock solutions ( $1 \mathrm{mM})$ were prepared for each tested compound. Reaction mixtures $(100 \mu \mathrm{L})$ were prepared by mixing $100 \mu \mathrm{M}$ of tested compound with ACh $70 \mu \mathrm{M}$. Final volume was completed with ammonium acetate solution $(15 \mathrm{mM}, \mathrm{pH} 8.0)$. Each reaction mixture $(10 \mu \mathrm{L})$ was injected into the LC-MS system and the percentage of inhibition was calculated in accordance with Eq. 1.

$$
\% \text { inhibition }=\left[1-\frac{\mathrm{Pi}}{P_{0}}\right] \times 100
$$

where, $\mathrm{P}$ is the attained peak area of Ch produced: (i) in the presence of the tested compound; (0) in the absence of the tested compound ${ }^{25-27}$.

Any possible interference at the $104 \mathrm{~m} / z$ range from the tested sample was evaluated injecting a reaction mixture without the substrate.

Cytotoxic activity. The cytotoxicity of compounds 1, 3, 5 and $\mathbf{6}$ was measured through the MTT (3-(4,5-dimethyl-2-thiazolyl)-2,5-diphenyl-2H-tetrazolium bromide) assay ${ }^{33}$, that is based in the conversion of the tetrazolium salt to a formazan product by viable cells. Two cell lines obtained from American Type Culture Collection (Manassas, Virginia, EUA) were used: HCT-116 (colorectal carcinoma, ATCC ${ }^{\circledR}$ CCL-247 ${ }^{\mathrm{TM}}$ ) and MCF-7 (breast adenocarcinoma, ATCC ${ }^{\circledR}$ HTB-22). The assay was conducted essentially as described by Monteiro et al. ${ }^{34}$. The HCT-116 and MCF-7 cells $\left(1 \times 10^{4}\right.$ cells well $\left.^{-1}\right)$ were seeded in 96 -well plates and, after $24 \mathrm{~h}$, different concentrations $(5 \mu \mathrm{M}$ and $50 \mu \mathrm{M})$ of the compounds were added and incubated for $72 \mathrm{~h}$. Doxorubicin $(0.003$ to $10 \mu \mathrm{M})$ and DMSO $(0.5 \%)$ were used as a positive and negative controls, respectively. At the end of incubation, the supernatant was replaced with fresh medium containing MTT $(0.5 \mathrm{mg} / \mathrm{mL})$ for $3 \mathrm{~h}$. The supernatant was, then, removed, and the MTT formazan product was dissolved in $150 \mu \mathrm{L}$ DMSO. The absorbance was measured using a multiplate reader (Multiskan ${ }^{\mathrm{TM}}$ FC, Thermo Scientific, Finland) at $570 \mathrm{~nm}$. All experiments were performed in duplicate. $\mathrm{IC}_{50}$ values, along with $95 \%$ confidence intervals, were calculated by non-linear regression using GraphPad Prism 5.0 (Intuitive Software for Science, La Jolla, CA, USA).

\section{Data Availability}

The authors declare availability to all data, materials or information contained in this manuscript.

\section{References}

1. Flewelling, A. J., Currie, J., Gray, C. A. \& Johnson, J. A. Endophytes from marine macroalgae: promising sources of novel natural products. Curr. Sci. 109, 88-111 (2015).

2. Medina, R. P. et al. Aromatic compounds produced by endophytic fungi isolated from red alga Asparagopsis taxiformis - Falkenbergia stage. Nat. Prod. Res. 33, 443-446 (2019).

3. Kuhnert, E. et al. Lenormandins A-G, new azaphilones from Hypoxylon lenormandii and Hypoxylon jaklitschii sp. nov., recognised by chemotaxonomic data. Fungal Divers. 71, 165-184 (2015).

4. Bussey, R. O. et al. Comparison of the chemistry and diversity of endophytes isolated from wild-harvested and greenhousecultivated yerba mansa (Anemopsis californica). Phytochem. Lett. 11, 202-208 (2015).

5. Oda, S., Fujinuma, K., Inoue, A. \& Ohashi, S. Synthesis of (-)- $\beta$-caryophyllene oxide via regio- and stereoselective endocyclic epoxidation of $\beta$-caryophyllene with Nemania aenea SF 10099-1 in a liquid-liquid interface bioreactor (L-L IBR). J. Biosci. Bioeng. 112, 561-565 (2011).

6. Giacobini, E. Cholinesterase inhibitors: new roles and therapeutic alternatives. Pharmacol. Res. 50, 433-440 (2004).

7. Heinrich, M. \& Teoh, H. L. Galanthamine from snowdrop - the development of a modern drug against Alzheimer's disease from local Caucasian knowledge. J. Ethnopharmacol. 92, 147-162 (2004).

8. Houghton, P. J., Ren, Y. \& Howes, M.-J. Acetylcholinesterase inhibitors from plants and fungi. Nat. Prod. Rep. 23, 181 (2006).

9. Hostettmann, K., Borloz, A., Urbain, A. \& Marston, A. Natural product inhibitors of acetylcholinesterase. Curr. Org. Chem. 10, 825-847 (2006).

10. Sangnoi, Y. et al. Acetylcholinesterase-inhibiting activity of pyrrole derivatives from a novel marine gliding bacterium, Rapidithrix thailandica. Mar. Drugs 6, 578-586 (2008).

11. Murray, A. P., Faraoni, M. B., Castro, M. J., Alza, N. P. \& Cavallaro, V. Natural AChE inhibitors from plants and their contribution to Alzheimer's disease therapy. Curr. Neuropharmacol. 11, 388-413 (2013).

12. Wibowo, M. et al. Cytotoxic sesquiterpenes from the endophytic fungus Pseudolagarobasidium acaciicola. Phytochemistry 122, 126-138 (2016)

13. Reino, J. L. et al. Chemical transformations on botryane skeleton. Effect on the cytotoxic activity. J. Nat. Prod. 66, 344-349 (2003).

14. Pescitelli, G., Di Bari, L. \& Berova, N. Conformational aspects in the studies of organic compounds by electronic circular dichroism. Chem. Soc. Rev. 40, 4603 (2011).

15. Batista, J. M. Jr., Blanch, E. W., Bolzani, V. \& da, S. Recent advances in the use of vibrational chiroptical spectroscopic methods for stereochemical characterization of natural products. Nat. Prod. Rep. 32, 1280-1302 (2015). 
16. Collado, I. G., Hernandez-Galan, R., Prieto, V., Hanson, J. R. \& Rebordinos, L. G. Biologically active sesquiterpenoid metabolites from the fungus Botrytis cinerea. Phytochemistry 41, 513-517 (1996).

17. Krohn, K. et al. Botryane metabolites from the fungus Geniculosporium sp. isolated from the marine red alga Polysiphonia. J. Nat. Prod. 68, 400-405 (2005).

18. Collado, I. G., Hernández-Galán, R., Durán-Patrón, R. \& Cantoral, J. M. Metabolites from a shake culture of Botrytis cinerea. Phytochemistry 38, 647-650 (1995).

19. Sprenger, R. et al. Solution-state conformations of natural products from chiroptical spectroscopy: the case of isocorilagin. Org. Biomol. Chem. 14, 3369-3375 (2016).

20. Durán-Patrón, R., Colmenares, A. J., Hernández-Galán, R. \& Collado, I. G. Some key metabolic intermediates in the biosynthesis of botrydial and related compounds. Tetrahedron 57, 1929-1933 (2001).

21. Collado, I. G., Sánchez, A. J. M. \& Hanson, J. R. Fungal terpene metabolites: biosynthetic relationships and the control of the phytopathogenic fungus Botrytis cinerea. Nat. Prod. Rep. 24, 674-686 (2007).

22. Kuhnert, E., Surup, F., Wiebach, V., Bernecker, S. \& Stadler, M. Botryane, noreudesmane and abietane terpenoids from the ascomycete Hypoxylon rickii. Phytochemistry 117, 116-122 (2015).

23. Yuan, Y. et al. A botryane metabolite with a new hexacyclic skeleton from an entomogenous fungus Hypocrea sp. Org. Lett. 15, 6050-6053 (2013).

24. Ren, F. et al. Hypocriols A-F, heterodimeric botryane ethers from Hypocrea sp., an insect-associated fungus. J. Nat. Prod. 79, 1848-1856 (2016).

25. Vanzolini, K. L., Vieira, L. C. C., Corrêa, A. G., Cardoso, C. L. \& Cass, Q. B. Acetylcholinesterase immobilized capillary reactorstandem mass spectrometry: an on-flow tool for ligand screening. J. Med. Chem. 56, 2038-2044 (2013).

26. Vilela, A. F. L., Seidl, C., Lima, J. M. \& Cardoso, C. L. An improved immobilized enzyme reactor-mass spectrometry-based label free assay for butyrylcholinesterase ligand screening. Anal. Biochem. 549, 53-57 (2018).

27. Seidl, C., Vilela, A. F. L., Lima, J. M., Leme, G. M. \& Cardoso, C. L. A novel on-flow mass spectrometry-based dual enzyme assay. Anal. Chim. Acta 1072, 81-86 (2019).

28. White, T. J., Bruns, T., Lee, S. \& Taylor, J. Amplification and direct sequencing of fungal ribosomal RNA genes for phylogenetics in PCR Protocols: A Guide to Methods and Applications (eds Innis, M. A., Gelfand, D. H., Sninsky, J. J. \& White, T. J.) 315-322 (Academic Press, 1990).

29. NCBI Resource Coordinators. Database resources of the National Center for Biotechnology Information. Nucleic Acids Res. 46, D8-D13 (2018).

30. Sánchez-Ballesteros, J. et al. Phylogenetic study of Hypoxylon and related genera based on ribosomal ITS sequences. Mycologia 92, 964-977 (2000).

31. Frisch, M. J. et al. Gaussian, Inc., Wallingford, CT, USA (2009).

32. Sarria, A. L. F. et al. Dimeric chalcones derivatives from Myracrodruon urundeuva act as cathepsin V inhibitors. Phytochemistry 154, 31-38 (2018).

33. Mossman, T. Rapid colorimetric assay for cellular growth and survival: application to proliferation and cytotoxicity assays. J. Immunol. Methods 65, 55-63 (1983).

34. Monteiro, A. F. et al. Oxidative functionalization of a halimane diterpenoid achieved by fungal transformation. Bioorg. Chem. 86, $550-556(2019)$

\section{Acknowledgements}

We acknowledge CAPES (Coordination for the Improvement of Higher Education Personnel) for a scholarship to R. P. M. (\#3334/15-5), CNPq (\#474270/2012-2) and FAPESP (Grants \#2013/07600-3; 2014/50926-0; 2014/252229; 2014-50299-5 - Bruker Daltonics Amazon Speed mass spectrometer; 2013/01710-1; 2015/17177-6) for financial support and fellowships. This research was also supported by resources supplied by the Centre for Scientific Computing (NCC/GridUNESP) of the São Paulo State University (UNESP). We also acknowledge Professor Marcos A. Soares for submitting the sequence of AT-05 fungal strain to GenBank.

\section{Author Contributions}

R.P.M. isolated the fungal strain AT-05, prepared its cultivation and extraction, isolated and identified all compounds and wrote the manuscript. A.R.A. supervised the fungal strain isolation, fermentation and extraction. J.M.B. Junior carried out computational calculations, VCD experiments and determined the absolute configurations. C.S. and A.F.L.V. performed the ChEIs screening assays and C.L.C. designed and supervised those experiments. H.V.D. performed the cytotoxic assay and L.V.C.L. supervised the experiment. R.J.A. identified the compounds and wrote/revised the manuscript. D.H.S.S. supervised all the experiments and wrote/revised the manuscript.

\section{Additional Information}

Supplementary information accompanies this paper at https://doi.org/10.1038/s41598-019-48655-7.

Competing Interests: The authors declare no competing interests.

Publisher's note: Springer Nature remains neutral with regard to jurisdictional claims in published maps and institutional affiliations.

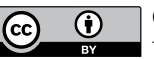

Open Access This article is licensed under a Creative Commons Attribution 4.0 International

License, which permits use, sharing, adaptation, distribution and reproduction in any medium or format, as long as you give appropriate credit to the original author(s) and the source, provide a link to the Creative Commons license, and indicate if changes were made. The images or other third party material in this article are included in the article's Creative Commons license, unless indicated otherwise in a credit line to the material. If material is not included in the article's Creative Commons license and your intended use is not permitted by statutory regulation or exceeds the permitted use, you will need to obtain permission directly from the copyright holder. To view a copy of this license, visit http://creativecommons.org/licenses/by/4.0/.

(c) The Author(s) 2019 